\title{
KAJIAN METODE UJI CEPAT SEBAGAI METODE RESMI PENGUJIAN KUALITAS BENIH TANAMAN HUTAN DI INDONESIA
}

\author{
Muhammad Zanzibar
}

\begin{abstract}
Physiological quality is one of the parameter used to determine the seed quality standard in a certification procedure. Information on the physiological quality often not readily available since germination test as a direst test takes time. Rapid test can predict the potency of a seed lot quickly yet accurately but it requires standardization of procedures and interpretation keys. This method relies on the tight correlation between physiological/development of a seed and its viability. In applying a rapid test, the suitability of the test toward the species needs to be determined. Compared to direct test, significant time saving are obtained for 13-34 days with TZ test, 13 - 44 days with cutting test and X-ray test, 7 - 25 days with hydrogen peroxide, 8 - 37 days with excision test and 12 - 19 days with leachate conductivity test. The TZ test and cutting test have been accommodated in the regulation on the physical and physiological test on forestry seeds. The other rapid tests such as excision, hydrogen peroxide, XC-Radiography and leachate conductivity need to be included in that regulation as well. The analyst for the rapid test for this rapid test should be an official that has been certified through intensive training.
\end{abstract}

Keywords: rapid test, physiological quality, seed forestry, certification

\section{PENDAHULUAN}

Saat ini informasi kualitas kelompok benih (seed lot) tanaman hutan diperoleh dari uji perkecambahan. Uji ini membutuhkan waktu yang relatif lama apalagi bila benih memiliki dormansi ganda. Selama jangka waktu tersebut, beberapa jenis akan cepat menurun viabilitasnya sehingga informasi pengujian tidak mencerminkan kualitas kelompok benih sesungguhnya.

Metode pendugaan kualitas, khususnya kualitas fisiologis yang dimaksudkan dalam tulisan ini dapat dilakukan melalui metode langsung dan tidak langsung. Metode langsung menggunakan indikator pertumbuhan kecambah; benih dikecambahkan pada kondisi ideal untuk berkecambah dan tumbuh, dilakukan di germinator, rumah kaca atau areal persemaian selama jangka waktu tertentu. Metode ini merupakan uji resmi dalam kegiatan sertifikasi benih tanaman hutan di Indonesia (RLPS, $2007)^{1}$. Metode tidak langsung didasarkan pada proses metabolisma benih serta kondisi fisik yang merupakan indikasi tidak langsung; disebut pula uji cepat viabilitas. Secara umum uji cepat memiliki dua tujuan (Willan, 1985), yaitu: (a) menentukan secara cepat kualitas benih suatu jenis yang berkecambah lambat atau menunjukkan dormansi di bawah perkecambahan normal (b) menentukan viabilitas potensial dari suatu kelompok benih.

Tulisan ini mengkaji kelayakan metode uji cepat sebagai metode resmi pendugaan kualitas benih tanaman hutan di Indonesia. Hasil kajian diharapkan dapat digunakan oleh institusi penguji benih tanaman hutan di Indonesia dan sebagai masukan kebijakan dalam meningkatkan pelayanan kepada pengguna, khususnya penyediaan informasi yang lebih cepat dan akurat.

\section{JENIS DAN PRINSIP DASAR METODE UJI CEPAT}

Beberapa metode uji cepat yang biasa digunakan untuk menduga kualitas benih adalah uji tetrazolium, uji hidrogen peroksida, uji belah, metode radiografi, uji eksisi embrio dan uji konduktivitas. Prinsip dasar beberapa metode tersebut adalah sebagai berikut:

A. Uji Tetrazolium ( $T Z$ test)

Prinsip metode TZ adalah bahwa setiap sel hidup akan berwarna merah oleh reduksi dari suatu pewarnaan garam tetrazolium dan membentuk endapan formazan merah, sedangkan sel-sel mati akan berwarna putih. Enzim yang mendorong terjadinya proses ini adalah dehidrogenase yang berkaitan dengan respirasi (Byrd, 1988). Kelebihan metode TZ meliputi waktu pengujian yang singkat, sangat tepat diaplikasikan pada benih yang mengalami dormansi serta benih yang mengalami pemasakan lanjutan (after ripening), tingkat ketelitian tinggi, sedangkan kelemahannya memerlukan keahlian dan pelatihan yang intensif, bersifat laboratoris, tidak dapat mendeteksi kerusakan akibat 
fungi atau mikroba lainnya dan bersifat merusak.

B. Uji Hidrogen Peroksida (Hydrogen peroxide test)

Metode pengujian hidrogen peroksida merupakan satu-satunya uji cepat yang dapat merangsang perkecambahan untuk tumbuh lebih cepat (Leadem, 1984). Hidrogen peroksida biasa pula digunakan untuk pematahan dormansi. Kelebihan metode hidrogen peroksida meliputi alat/bahan tidak mahal, bersifat objektif dan sederhana dalam penyiapannya, sedangkan kekurangannya tidak praktis pada benih berukuran kecil, waktu uji relatif lama $(4-8$ hari) dan bersifat merusak.

C. Uji Eksisi Embrio (excision Embryo Test)

Determinasi terhadap benih hidup/mati ditentukan oleh perilaku embrio selama masa inkubasi. Menurut Bonner et al (1994), kelebihan metode eksisi adalah peralatan pengujian cukup sederhana, hasil uji merupakan kondisi benih sebenarnya, mudah dievaluasi dan memiliki nilai khusus pada benih yang mengalami dormansi embrio, sedangkan kekurangannya bersifat labour intensive, waktu yang relatif panjang dalam mempersiapkan benih sebelum diuji, bersifat merusak dan relatif lambat $(4-8$ hari).

D. Uji Belah (Cutting Test)

Uji ini umumnya digunakan di lapangan dalam kegiatan pengumpulan/produksi untuk memperkirakan tingkat kemasakan. Menurut Bonner et al (1994), kelebihan metode ini meliputi pengujian dapat dilaksakan dengan cepat dan murah, pada benih berukuran besar/segar hasil pengujiannya relatif akurat, sedangkan kekurangannya sulit dilakukan pada benih berukuran kecil, memberikan hasil pengujian yang tidak tepat untuk benih yang telah disimpan dan merupakan uji yang merusak.

E. Uji Konduktivitas (Leachate Conductivity Test)

Prinsip uji konduktivitas adalah bahwa benih hidup/mati akan memberikan reaksi yang berbeda jika dialiri arus listrik. Uji konduktivitas merupakan pengujian secara fisik untuk melihat tingkat kebocoran sel. Struktur membran sel yang jelek akan menyebabkan kebocoran sel yang erat kaitannya dengan benih bervigor rendah. Byrd (1988), kelebihan dari metode konduktivitas meliputi hasil pengujian bersifat objektif, tidak merusak, waktu pengujian relatif cepat ( 2 hari), sedangkan kekurangannya adalah biayanya relatif mahal, diperlukan keterampilan teknik yang memadai, tidak dapat digunakan untuk mengukur setiap individu benih.

F. Uji Kontras Radiografi (XC-Radiography Test)

Metode kontras radiografi memanfaatkan sifat sinar $x$ yang dilalukan terhadap spesimen. Metode ini mampu menganalisa sifat dari struktur benih. Sifat-sifat yang dimaksud tidak hanya berkaitan dengan anatomi dan kerusakan/kematian jaringan dalam benih, tetapi juga menyangkut perubahan fisiologis selama masa pematangan dan perkecambahan dengan menggunakan bahan pengontras (Simak, 1980). Kelebihan metode kontras radiografi yaitu cepat memberikan hasil pengujian, memberikan bukti pengujian yang permanen (foto/radiograf) dan tidak bersifat merusak, sedangkan kekurangannya adalah peralatannya sangat mahal, memerlukan latihan yang ekstensif dan interpretasi hasil bersifat subjektif.

\section{PENGEMBANGAN DAN APLIKASI METODE UJI CEPAT}

Tingkat akurasi tinggi dimungkinkan bila penilaian dilakukan secara objektif melalui pengembangan metode, diantaranya standardisasi prosedur (termasuk alat dan bahan) dan kunci interpretasi, sedangkan pertimbangan lainnya adalah kesesuaian metode terhadap jenis yang diuji.

\subsection{Standardisasi Prosedur Pengujian}

Pengamatan pada uji cepat membutuhkan kehati-hatian, keahlian, ketelitian dan pengalaman analis. Standardisasi prosedur meliputi standarisasi bahan/alat, sterilisasi, pengambilan contoh dan proses pengujian.

Bahan-bahan umumnya mudah diperoleh dan harganya relatif terjangkau, kecuali mesin radiografi pada uji kontras radiografi yang membutuhkan investasi besar. Alat pengukur konduktivitas, oven dan inkubator telah menjadi peralatan standar setiap institusi penguji mutu. Sterilisasi dimaksudkan agar semua bahan mapun peralatan dalam kondisi aseptik karena sel/jaringan sangat mudah terkontaminasi mikroba, khususnya pada kondisi benih tanpa kulit. Pengambilan contoh dimaksudkan agar benih yang diuji benar-benar mewakili kelompoknya. Metode pengambilan contoh dapat menggunakan cara acak parohan atau 
menggunakan alat pembagi benih (RLPS, 2007) $)^{2}$.

Dalam melakukan pengujian, tahapan terpenting dari masing-masing metode perlu dipahami oleh analis karena setiap tahapan memiliki tujuan khusus. Bahan/alat serta tahapan terpenting dari masing-masing metode disajikan pada Tabel 1.

\subsection{Standardisasi Kunci Interpretasi}

Pemahaman mengenai struktur tumbuh (kulit benih, embrio dan endosperm/kotiledon) merupakan modal penting dalam mengevaluasi hasil. Untuk menyederhanakan atau memudahkan analis dibutuhkan kunci interpretasi yang dibuat berdasarkan penilaian kualitas masing-masing metode terhadap uji perkecambahan langsung (kalibrasi).

Secara umum, kunci interpretasi/kriteria benih hidup/benih mati beberapa jenis tanaman hutan (Zanzibar et al 2003), adalah sebagai berikut: Uji TZ, semakin luas pola pewarnaan, intensitas tinggi serta posisi dari pola pewarnaan terletak pada struktur tumbuh benih menunjukkan peluang sebagai benih hidup semakin tinggi dan sebaliknya. Uji hidrogen peroksida, benih dianggap hidup apabila radikel muncul pada ujung benih yang dipotong, sedangkan jika radikel tidak muncul maka dianggap mati. Uji eksisi embrio, benih hidup dicirikan apabila radikel dan plumula mengalami pertumbuhan, embrio tetap kokoh/segar (berwarna putih atau putih kehijauan), sedangkan benih mati apabila tidak terjadi pertumbuhan pada radikel dan plumula, embrio cepat rusak/membusuk, berwarna putih kecoklatan. Uji belah, benih hidup apabila struktur tumbuh berwarna kuning atau kuning kehijauan, kondisinya segar serta tanpa kerusakan mekanis pada bagian struktur tumbuh penting, benih mati dicirikan oleh layunya struktur tumbuh, tidak segar dan berbau busuk. Uji konduktivitas dilakukan pada sekelompok benih bukan pada individu/sel/jaringan, kelompok benih yang memiliki konduktivitas elektrik tinggi diasumsikan memiliki viabilitas dan vigor rendah, demikian sebaliknya, sedangkan uji kontras radiografi ciri benih hidup bila endosperm memenuhi lokus, embrio berkembang sempurna, tidak keriput dan tidak teresapi bahan pengontras, sedangkan benih mati endospermnya tidak berkembang/kosong, embrio rusak karena mekanis/serangga dan teresapi bahan pengontras. Contoh kunci interpretasi dapat dilihat pada Gambar 1.

Telah banyak penelitian yang menunjukkan adanya hubungan yang erat antara kondisi sel/jaringan dan viabilitas benih. Untuk ilustrasi keeratan hubungan antara uji cepat dan uji perkecambahan beberapa jenis tanaman hutan dapat dilihat pada Tabel 2.

Keakuratan metode kontras radiografi sangat ditentukan oleh kualitas radiograf, seperti halnya dalam praktek kedokteran yang membutuhkan ketelitian tinggi. Contoh kunci radiograf benih hidup/mati beberapa jenis tanaman hutan dapat dilihat dalam Kobmo dan Skeates (1986). Menurut Grabe dalam Pramono et al (2001), hasil uji cepat dan uji perkecambahan yang dilaksanakan secara tepat umumnya memiliki nilai yang saling mendekati dalam selang keragaman pengambilan contoh normal. Perbedaan $3-5 \%$ secara keseluruhan dapat diartikan tidak terjadi kesalahan dalam pengambilan contoh. Perbedaan yang besar antara hasil uji perkecambahan dan uji cepat yang sangat mempengaruhi akurasi hasil disebabkan antara lain: (1) Perbedaan contoh benih (2) Teknik pengujian perkecambahan atau uji cepat yang kurang tepat (3) Dormansi benih (4) Benih keras (5) Benih terserang hama/penyakit (6) Kerusakan karena kimiawi.

\subsection{Kesesuaian Jenis terhadap Metode}

Faktor yang mempengaruhi kesesuaian jenis terhadap metode tertentu adalah karakter, ukuran, tipe dormansi dan ketahanan benih dalam kondisi tanpa kulit.

Pengetahuan tentang karakter benih memberikan petunjuk bagaimana benih tersebut ditangani agar tetap memiliki vigor optimum hingga akan ditanam kembali, demikian juga dalam pengujian kualitasnya, yaitu harus diuji dengan metode yang lebih cepat (TZ, uji belah dan kontras radiografi). Zanzibar dan Yuniarti (2006), benih T. grandis (jati) memiliki dormansi ganda, berturut-turut metode uji yang sesuai adalah eksisi, uji belah dan kontras radiografi. Jika menggunakan metode TZ, hidrogen peroksida dan konduktivitas benih telanjang cepat menjadi rusak. Pada Tabel 3 disajikan kesesuaian jenis terhadap metode berdasarkan pertimbangan faktor dalam/luar benih dan perkiraan waktu uji.

Metode TZ merupakan metode yang paling sesuai pada hampir semua jenis, sedangkan uji konduktivitas sangat terbatas penggunaannya. Hal ini telah sesuai dengan rekomendasi ISTA (International Seed Testing Acosiation) sejak tahun 1976, agar metode TZ digunakan secara luas untuk pengujian kualitas benih jenis daun lebar dan konifer. 
Waktu yang dapat dihemat sangat signifikan jika menggunakan uji cepat dibandingkan

metode perkecambahan (Tabel 3).

Tabel 1 Bahan dan Alat Beberapa Metode Uji Cepat untuk Pengujian Kualitas Benih Tanaman Hutan

\begin{tabular}{|c|c|c|c|c|}
\hline Metode Uji & Bahan & Alat & Tahapan Penting & Tujuan \\
\hline $\mathrm{TZ}$ & $\begin{array}{l}\text { - garam tetrazolium } \\
\text { (2,3,5-triphenil } \\
\text { tetrazolium klorida), } \\
\mathrm{Na}_{2} \mathrm{HPO}_{4 \cdot 2} \mathrm{H}_{2} \mathrm{O} \text { dan } \\
\mathrm{KH}_{2} \mathrm{PO}_{4} \\
\text { - etanol, akuades, } \\
\text { kertas merang dan } \\
\text { aluminium foil }\end{array}$ & $\begin{array}{l}\text { loup, cawan petri, } \\
\text { gelas piala, } \\
\text { gunting, pinset, } \\
\text { oven, pengaduk, } \\
\text { saringan, } \\
\text { semprotan } \\
\text { tangan, } \\
\text { timbangan dan } \\
\text { alat pembagi } \\
\text { benih }\end{array}$ & 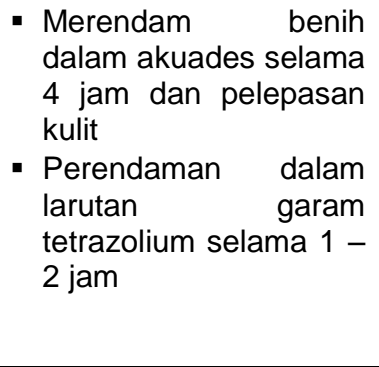 & $\begin{array}{l}\text { - Mengaktifkan } \\
\text { sel/jaringan benih } \\
\text { - Membedakan antara } \\
\text { sel/jaringan hidup/mati }\end{array}$ \\
\hline $\begin{array}{l}\text { Hidrogen } \\
\text { Peroksida }\end{array}$ & $\begin{array}{ll}\text { - } & \mathrm{H}_{2} \mathrm{O}_{2} \\
\text { - } & \text { benomil, etanol, } \\
& \text { akuades, kertas } \\
\text { merang ran } & \text { dan } \\
& \text { aluminium foil }\end{array}$ & $\begin{array}{l}\text { cawan petri, gelas } \\
\text { piala, gunting, } \\
\text { pinset, oven, } \\
\text { pengaduk, } \\
\text { saringan, } \\
\text { semprotan } \\
\text { tangan, } \\
\text { timbangan, } \\
\text { penggaris dan } \\
\text { alat pembagi } \\
\text { benih }\end{array}$ & $\begin{array}{l}\text { - Pemotongan kulit } \\
\text { pada ujung radikel } \\
\text { - Aerasi larutan selama } \\
\text { pengujian ( } 3-7 \text { hari) }\end{array}$ & $\begin{array}{l}\text { - Meningkatkan imbibisi } \\
\text { larutan ke dalam benih } \\
\text { dan memacu } \\
\text { pertumbuhan } \\
\text { - Meningkatkan jumlah } \\
\text { oksigen terlarut dan } \\
\text { mengurangi } \\
\text { kontaminasi mikroba }\end{array}$ \\
\hline $\begin{array}{l}\text { Eksisi } \\
\text { Embrio }\end{array}$ & $\begin{array}{lr}\text { Benomil, etanol, } \\
\text { akuades, } & \text { kertas } \\
\text { saring } & \text { dan } \\
\text { aluminium foil } & \end{array}$ & $\begin{array}{l}\text { - inkubator, } \\
\text { laminar air flow } \\
\text { (jika ada) } \\
\text { - loup, cawan } \\
\text { petri, gelas } \\
\text { piala, gunting, } \\
\text { pinset, } \\
\text { saringan, } \\
\text { semprotan } \\
\text { tangan, } \\
\text { timbangan, } \\
\text { dan alat } \\
\text { pembagi benih }\end{array}$ & $\begin{array}{l}\text { - Merendam benih } \\
\text { dalam akuades selama } \\
4 \text { jam } \\
\text { - Eksisi embrio dan } \\
\text { inkubasi (3 - } 7 \text { hari) }\end{array}$ & $\begin{array}{ll}\text { - } & \text { Mengaktifkan } \\
\text { sel/jaringan benih } \\
\text { - } \\
\text { Memacu/mengetahui } \\
\text { pertumbuhan embrio }\end{array}$ \\
\hline Uji Belah & $\begin{array}{l}\text { - kertas } \\
\text { saring/merang }\end{array}$ & $\begin{array}{l}\text { - pisau, silet, } \\
\text { gunting, ragum }\end{array}$ & $\begin{array}{l}\text { - } \text { Perendaman dalam } \\
\text { akuades selama } 4 \text { jam } \\
\text { - } \text { Membelah benih } \\
\text { searah longitudinal }\end{array}$ & $\begin{array}{l}\text { - Mengaktifkan } \\
\text { sel/jaringan benih } \\
\text { - Mengetahui kondisi } \\
\text { struktur tumbuh }\end{array}$ \\
\hline $\begin{array}{l}\text { Uji } \\
\text { Konduktivitas }\end{array}$ & $\begin{array}{l}\text { - Akuabides } \\
\text { - akuades }\end{array}$ & $\begin{array}{l}\text { - conductivity } \\
\text { meter, } \\
\text { inkubator } \\
\text { - gelas piala, } \\
\text { pinset, } \\
\text { pengaduk, } \\
\text { saringan dan } \\
\text { alat pembagi } \\
\text { benih } \\
\end{array}$ & \begin{tabular}{l} 
- Mencuci benih pada \\
air mengalir \\
- Merendam benih \\
dalam \\
akuabides larutan \\
menginkubasikannya \\
\multicolumn{2}{l}{ selama 24 jam }
\end{tabular} & $\begin{array}{l}\text { - Membersihkan kotoran } \\
\text { karena kotoran akan } \\
\text { meningkatkan nilai } \\
\text { konduktivitas elektrik } \\
\text { larutan yang akan diuji } \\
\text { - Mengeluarkan zat-zat } \\
\text { eksudat di dalam } \\
\text { benih dan mengetahui } \\
\text { tingkat kebocoran sel }\end{array}$ \\
\hline $\begin{array}{l}\text { Kontras } \\
\text { Radiografi }\end{array}$ & $\begin{array}{l}\text { - Bahan pengontras: } \\
\mathrm{BaCl}_{2}, \mathrm{Nal}, \mathrm{KI} \text {, film, } \\
\text { kertas foto, bahan } \\
\text { cuci cetak (x-ray } \\
\text { rapid developer dan } \\
\text { x ray express } \\
\text { fixative) } \\
\text { - akuades }\end{array}$ & $\begin{array}{l}\text { - } \text { mesin sinar } x \text {, } \\
\text { kaset film, } \\
\text { layar pendar } \\
\text { - kamera, pinset, } \\
\text { bak plastik dan } \\
\text { alat pembagi } \\
\text { benih }\end{array}$ & $\begin{array}{l}\text { - Penentuan parameter } \\
\text { penyinaran (KVp, mA, } \\
\text { eT, FFD) } \\
\text { - Perendaman dalam } \\
\text { bahan pengontras }\end{array}$ & $\begin{array}{l}\text { - Mendapatkan radiograf } \\
\text { yang baik } \\
\text { - Mengetahui } \\
\text { sel/jaringan hidup/mati }\end{array}$ \\
\hline
\end{tabular}


(a)
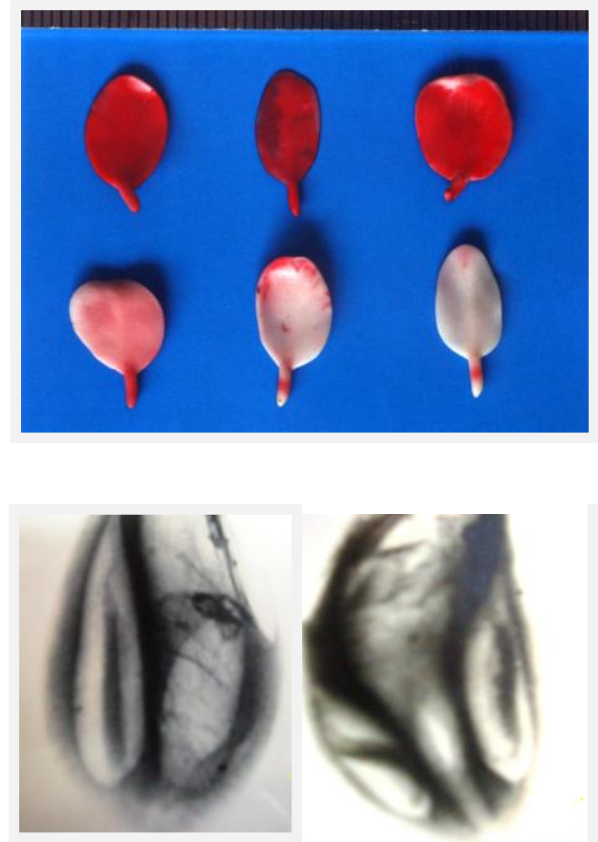

(c)

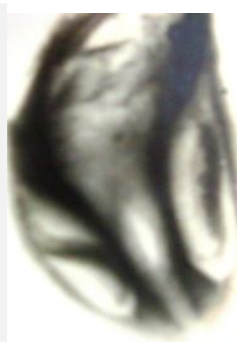

(d) (b)
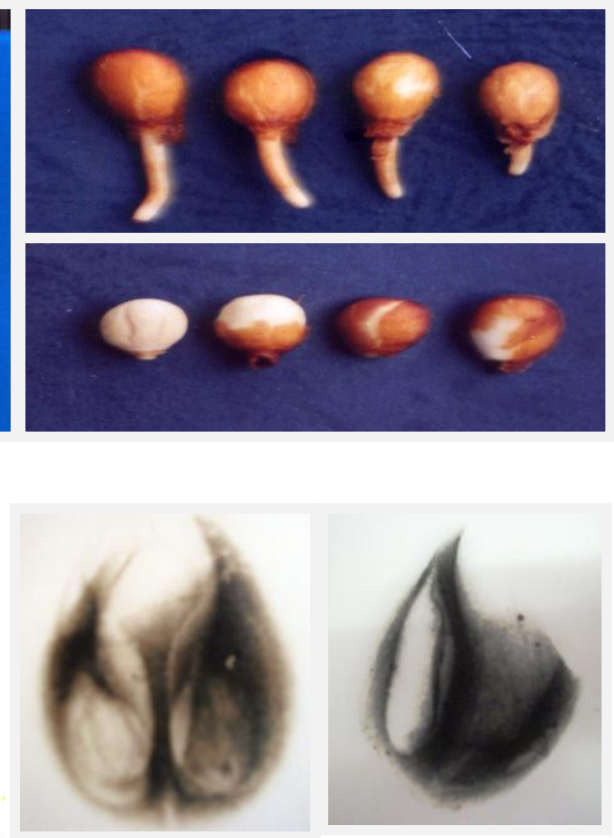

(e)

Gambar 1 Kriteria Benih Hidup dan Mati Beberapa Metode Uji Cepat.

(a) Metode TZ pada Manilkara kauki

(b) Metode Hidrogen Peroksida pada Agathis loranthifolia

(c) Metode Eksisi Embrio pada Dalbergia latifolia

(d) Metode Kontras Radiografi pada Gmelina arborea. $\mathrm{H}=$ Benih Hidup, $\mathrm{M}=$ Mati (Foto doc.M. Zanzibar)

Penghematan waktu uji TZ antara $13-34$ hari, uji belah dan kontras radiografi antara $13-$ 44 hari, hidrogen peroksida antara $7-25$ hari, eksisi antara 8 - 37 hari, sedangkan uji konduktivitas antara 12 - 19 hari. Untuk aplikasi, setelah benih diserahkan di laboratorium segera dilaksanakan pengujian agar dugaan kualitas kelompok benih lebih awal diperoleh. Hal yang sama juga dilakukan oleh AOSA (Assiciation of Seed Analysts) di Amerika, uji perkecambahan tetap sebagai uji resmi, namun uji cepat selalu digunakan sebagai metode pembanding.

\subsection{Hal-Hal Lain}

Uji cepat yang direkomendasikan sebagai metoda penilaian kualitas fisik dan fisiologis benih tanaman hutan adalah uji TZ dan belah, namun tidak dapat digunakan dalam penerapan aspek legalitas (RLPS, 2007). Meskipun hanya merupakan metoda pembanding, penilaian berdasarkan metoda tersebut menjadi syarat penting untuk kemudian didokumentasikan oleh institusi penguji mutu. Dengan demikian fungsi pelayanan penyediaan informasi yang cepat dan akurat dapat terwujud. Adapun uji-uji lainnya, perlu pula diakomodasi dalam peraturan pengujian karena ke dua metoda tersebut tidak dapat digunakan untuk semua jenis. Analis perlu mendapatkan pelatihan yang intensif, dalam melakukan pengujian seharusnya mereka telah mendapatkan sertifikasi keahlian uji cepat. 
Tabel 2 Model Pendugaan Kualitas Beberapa Benih Tanaman Hutan Berdasarkan Uji Cepat Viabilitas

\begin{tabular}{|c|c|c|c|c|}
\hline Species & Metode & Model Penduga & $\mathbf{R}^{2}$ & Sumber \\
\hline \multirow[t]{5}{*}{$\begin{array}{l}\text { P. falcataria } \\
\text { (sengon) }\end{array}$} & $\mathrm{TZ}$ & $Y=1.10 X-7.83$ & 0,93 & $\begin{array}{l}\text { Zanzibar dan Herdiana } \\
\text { (2006) }\end{array}$ \\
\hline & $\begin{array}{l}\text { Hidrogen } \\
\text { peroksida }\end{array}$ & $Y=1.10 X-7.3$ & 0,84 & $\begin{array}{l}\text { Zanzibar dan Herdiana } \\
\text { (2006) }\end{array}$ \\
\hline & Eksisi embrio & $Y=0.93 X-1.1$ & 0,78 & $\begin{array}{l}\text { Zanzibar dan Herdiana } \\
\text { (2006) }\end{array}$ \\
\hline & Belah & $Y=1.26 X-23.4$ & 0.77 & $\begin{array}{l}\text { Zanzibar dan Herdiana } \\
\text { (2006) }\end{array}$ \\
\hline & Konduktivitas & $\begin{array}{l}Y=231.22-36.78 \\
\ln x_{1}\end{array}$ & 0.67 & Nugroho (1998) \\
\hline \multirow[t]{5}{*}{$\begin{array}{l}\text { A. mangium } \\
\text { (akasia) }\end{array}$} & $\mathrm{TZ}$ & $Y=0.94 X+4.19$ & 0.93 & $\begin{array}{l}\text { Zanzibar dan Herdiana } \\
\text { (2005) }\end{array}$ \\
\hline & $\begin{array}{l}\text { Hidrogen } \\
\text { peroksida }\end{array}$ & $Y=1.13 X-9.99$ & 0.90 & $\begin{array}{l}\text { Zanzibar dan Herdiana } \\
\text { (2005) }\end{array}$ \\
\hline & Eksisi embrio & $Y=0.74 X+21.72$ & 0.81 & $\begin{array}{l}\text { Zanzibar dan Herdiana } \\
\text { (2005) }\end{array}$ \\
\hline & Belah & $Y=1.21 X+23.71$ & 0.85 & $\begin{array}{l}\text { Zanzibar dan Herdiana } \\
\text { (2005) }\end{array}$ \\
\hline & Konduktivitas & $Y=94.51-0.47 x_{1}$ & 0.55 & Sitepu (1998) \\
\hline $\begin{array}{l}\text { Pinus radiata } \\
\text { (loblolly) }\end{array}$ & Konduktivitas & $Y=104-1.91 x_{1}$ & 0.74 & Bonner dan Vozzo (1986) \\
\hline $\begin{array}{l}\text { E.cyclocarpum } \\
\text { (sengon buto) }\end{array}$ & Konduktivitas & $\begin{array}{l}Y=41.06-14.90 \mathrm{In} \\
X_{I}\end{array}$ & 0.84 & Nugroho (1998) \\
\hline $\begin{array}{ll}O . & \text { bicolor } \\
\text { (balsa) } & \end{array}$ & Konduktivitas & $Y=143.92-0.68 x_{1}$ & 0.83 & Sitepu (1998) \\
\hline
\end{tabular}

Keterangan:

$\mathrm{Y} \quad=$ Daya berkecambah

$\mathrm{X} \quad=$ Nilai dugaan daya berkecambah berdasarkan metode TZ, hidrogen peroksida, eksisi dan belah

$\mathrm{XI} \quad=$ nilai daya hantar listrik

Tabel 3 Kesesuian Jenis dan Prakiraan Waktu Uji Beberapa Benih Tanaman Hutan

\begin{tabular}{|c|c|c|c|c|c|c|c|c|}
\hline \multirow[b]{2}{*}{ NO } & \multirow[b]{2}{*}{ Jenis } & \multicolumn{6}{|c|}{ Metode Uji Cepat ${ }^{1)}$} & \multirow{2}{*}{$\begin{array}{c}\text { Waktu uji } \\
\text { Perkecamba } \\
\text { han (hari) }\end{array}$} \\
\hline & & TZ & $\begin{array}{l}\text { Hidrogen } \\
\text { Peroksida }\end{array}$ & $\begin{array}{l}\text { Eksisi } \\
\text { Embrio }\end{array}$ & $\begin{array}{c}\text { Uji } \\
\text { Belah }\end{array}$ & Konduk & $\begin{array}{c}\text { Kontras } \\
\text { Rasiografi }\end{array}$ & \\
\hline \multicolumn{9}{|c|}{ Karakter: Ortodoks } \\
\hline 1 & Acacia spp (akasia) & $* * * * / 1$ & $* \star / 7$ & $* * * / 6$ & $* / 1$ & $* * / 2$ & $* / 1$ & 14 \\
\hline 2 & $\begin{array}{l}\text { S. macrophylla } \\
\text { (mahoni) }\end{array}$ & $* \star \star * / 1$ & $\star \star / 7$ & $\star \star / 7$ & $\star \star \star / 1$ & - & $* / 1$ & 28 \\
\hline 3 & T. grandis (jati) & - & - & $\star \star \star / 8$ & $\star \star \star \star / 1$ & - & $* * / 1$ & 45 \\
\hline 4 & P. falcataria (sengon) & $* * * * / 1$ & $* * / 7$ & $* * \star / 4$ & $* * * / 1$ & $* / 2$ & $* / 1$ & 14 \\
\hline
\end{tabular}




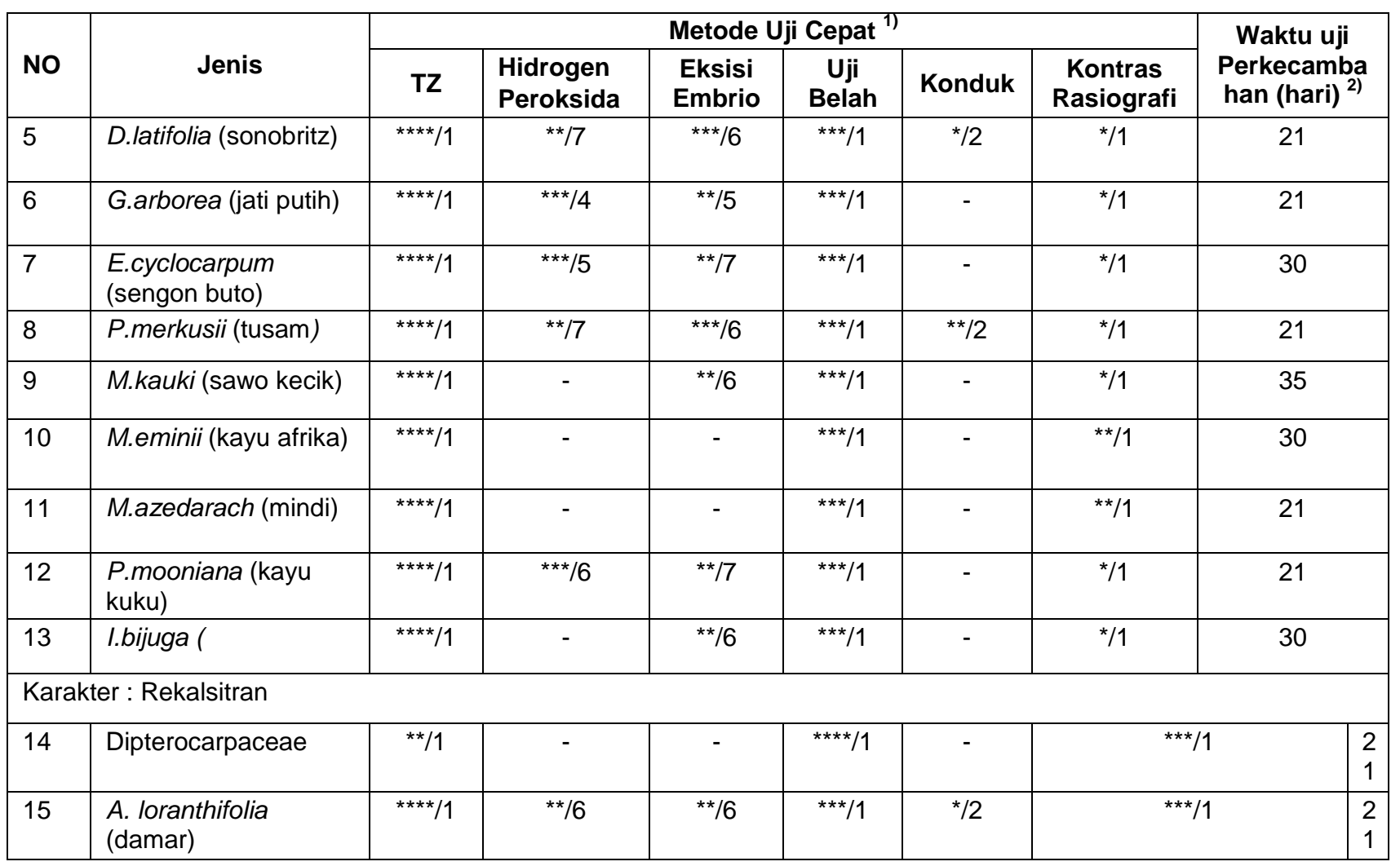

Keterangan: ${ }^{* * * *} / 1$ = Metoda paling sesuai/1 hari waktu pengujian metoda uji cepat Sumber: ${ }^{1)}$ Zanzibar dan Yuniarti (2006), ${ }^{2)}$ RLPS $(2007)^{2}$

\section{KESIMPULAN DAN SARAN}

\subsection{Kesimpulan}

- Uji cepat memiliki potensi yang sangat besar untuk menjadi metoda resmi pengujian kualitas benih tanaman hutan di Indonesia.

- Hasil pengujian yang objektif sangat ditentukan oleh standardisasi prosedur dan kunci interpretasi, serta pertimbangan kesesuaian metoda terhadap jenis yang diuji.

\subsection{Saran}

- Perlu adanya kebijakan yang mendukung penggunaan metode uji cepat, selain uji TZ dan uji belah dalam kegiatan sertifikasi benih tanaman hutan.

- Untuk aplikasi secara luas, dibutuhkan pelatihan analis dan sertifikasi keahlian uji cepat.

\section{DAFTAR PUSTAKA}

1. Bonner, F.T and J. Vozzo. 1986. Estimating Seed Quality of Southern Pines by Leachate
Conductivity. United State Departmen of Agriculture, Forest Service, Southern Forest Experiment Station. Starkville, MS.

2. M.W. Elam and S.B. Land Jr. 1994. Tree Seed Technology Training Course: Instructors Manual. United State Departmen of Agriculture, Forest Service, Southern Forest Experiment Station. New Orleans.

3. Byrd, H.W. 1988. Pedoman Teknologi Benih (Terjemahan). State College. Mississipi.

4. Kobmoo, B and Skeates, 1986. Xradiography of Tropical Forest Tree seed. The Embryon. 2 (1): 25 - 28.

5. Leadem, C.L. 1984. Quick Test for Tree Seed Viability. Management Report NO 18. B.C. Ministry Forest Land Research Branch.

6. Nugroho, A.A. 1998. Pendugaan Kualitas Benih Acacia mangium willd dan Ochroma bicolor Berdasarkan Uji Daya Hantar Listrik. Jurusan Manajemen Hutan, Fakultas Kehutanan IPB. Skripsi.

7. Pramono.A.A, Danu dan D. Iriantono. 2001. Standar Pola Pewarnaan Tetrazolium Untuk Uji Cepat Viabilitas Benih Pinus merkusii (tusam). Buletin Teknologi Perbenihan. Balai Teknologi Perbenihan. Badan 
Penelitian dan Pengembangan Kehutanan. Departemen Kehutanan.

8. RLPS, 20071. Peraturan Direktur Jenderal Rehabilitasi Lahan dan Perhutanan Sosial, Nomor: P. $04 \quad$ N-PTH/2007 tentang Pedoman Sertifikasi Mutu Benih Tanaman Hutan IDitjen RLPS, Departemen Kehutanan.

9. Peraturan Direktur Jenderal Rehabilitasi Lahan dan Perhutanan Sosial, Nomor: P. 13 /V-PTH/2007 tentang Petunjuk Teknis Pengujian Mutu Fisik - Fisiologis Benih. Ditjen RLPS, Departemen Kehutanan.

10. Simak,M. 1980. The X-Radiography in researc and testing of forest tree seeds. The Swedish University of Agricultural Science, Department of Silviculture. Umea.

11. Sitepu, S.M. 1998. Pendugaan Kualitas Benih Enterolobium cyclocarpum dan Paraserianthes falcataria Berdasarkan $\mathrm{Uji}$ Daya Hantar Listrik. Jurusan Manajemen Hutan, Fakultas Kehutanan IPB. Skripsi. Bogor.

12. Willan, R.L. 1985. A Guide to Forest Seed Handling. DANIDA Forest Seed Centre Hunleabaek Denmark - FAO.

13. Zanzibar, $M$, Asep R, Nanang $H$, Safrudin $M$, Enok R.K dan Adang M. 2003. Pedoman Uji Cepat Viabilitas Benih Tanaman Hutan. Buku I. Balai Litbang Teknologi Perbenihan. Badan Penelitian dan Pengembangan Kehutanan. Departemen Kehutanan
14. ---------- dan Nanang Herdiana. 2005. Ketepatan Beberapa Metoda Uji Cepat Dalam Menduga Viabilitas Benih Mangium. Jurnal Penelitian Hutan Tanaman, Vol. 2, Suplemen NO. 02. Badan Penelitian dan Pengembangan Kehutanan. Departemen Kehutanan.

15. Anonim. 2006. Akurasi Metoda Uji Cepat Dalam Menduga Viabilitas Benih Sengon. Jurnal Penelitian Hutan Tanaman, Vol. 3, Suplemen NO. 02. Badan Penelitian dan Pengembangan Kehutanan. Departemen Kehutanan.

16. Naning Yuniarti. 2006. Standar Prosedur dan Kunci Interpretasi Beberapa Benih Tanaman Hutan. Prosiding Seminar Hasil-Hasil Penelitian Balai Litbang Teknologi Perbenihan. Badan Penelitian dan Pengembangan Kehutanan. Departemen Kehutanan.

\section{BIODATA}

\section{Muhammad Zanzibar}

Penulis dilahirkan di Muna pada tanggal 8 Juni 1960. Penulis menyelesaikan pendidikan Magister Management di Universitas Ars International Bandung pada tahun 2002. Saat ini Penulis bekerja sebagai Peneliti Madya Bidang Silvikultur pada Balai Penelitian Teknologi Perbenihan, Badan Litbang Kehutanan, Bogor. Penulis dapat dihubungi di alamat email: muhammadzanzibar@yahoo.com. 